Asian Journal of Information Technology 9 (3): 123-132, 2010

ISSN: $1682-3915$

(C) Medwell Journals, 2010

\title{
The Influence of E-mail on Students' Learning in Higher Education: An Extension to the Technology Acceptance Model (TAM)
}

\author{
${ }^{1} \mathrm{~J}$. Macharia and ${ }^{2} \mathrm{E}$. Nyakwende \\ ${ }^{1}$ United States International University, Nairobi, Kenya \\ ${ }^{2}$ North-West University, Mafikeng Campus Mambatho, South Africa
}

\begin{abstract}
Universities round the world are transitioning to innovative and better e-mail systems with the aim of attaining improved student output and interaction than ever before. Studies have shown that this expectation usually fails since technology deployment does not necessarily lead to utilization for improved learning and teaching. To understand this failure in enhancement of student productivity and learning outcomes, this study investigates the factors in students learning that affect the adoption and diffusion of e-mail in institutions of higher learning. This was done by modelling the relationships between variables that influence e-mail use and learning, using Technology Acceptance Model (TAM). This study sampled 1092 male and female responses via a cross-sectional survey instrument. The sample drew from public and private universities students using e-mail systems in their universities in Kenya. The results show that voluntariness influences the diffusion of e-mail and its use and consequently students learning. Further Perceived Usefulness (PU), Perceived Ease of Use (PEOU) and Perceived enjoyment of e-mail systems are related to their use. The contribution of thisstudy lies in positing e-mail effects on student learning can improve if vendors develop user friendly and easy to use e-mail systems. This can minimize variations in e-mail use and consequently leverage e-mail usage as a tool that enhances student learning in an educational setup.
\end{abstract}

Key words: E-mail, diffusion, learning, TAM, higher education

\section{INTRODUTION}

Higher education institutions globally are migrating to innovative and improved e-mail systems with the aim of attaining improved student learning. However, several studies have posited that after e-mail migration to better systems, the results do not necessarily show significant improvement in students productivity (Kanungo and Jain, 2008). Among the probable causes of such failures is the fact that technology rejection is common (Davis, 1989). E-mail is available everywhere from the internet to mobile phones and is a necessary productivity tool that is most successful among networked applications (Kanungo and Jain, 2008). However, the problem of e-mail backlog due to the result of receiving too many junk or spam e-mails resulting to a demand for huge memory storage and e-mail maintenance such as filing, archiving, tagging and searching of e-mails have emerged to be productivity hindrances (Kanungo and Jain, 2008). Consequently, there is an urgent need to understand this phenomenon. This paper has therefore aims to investigate the determinant factors that influence students e-mail adoption, diffusion and usage.
Most universities e-mail transitions are moving to Google powered systems or the UNIX based Web mail. These systems and other e-mail developments make it possible for more users to receive and send increased number of e-mails than before. Consequently, it is expected that the innovative e-mail systems would improve student's productivity considerably. However, the factors that hinder or promote the productivity of many users have not been investigated adequately. Thus, in order to identify these factors that increase e-mail adoption and diffusion by students for their learning and hence improvement in individual productivity, this study led the associations among factors affecting e-mail behavioural intention and usage. It seems that the advantages of improved ease of e-mail use and perceived usefulness in student learning influences e-mail diffusion. The research is conducted this research in two phases: developing a dynamic TAM model of e-mail use and modelling different scenarios to analyze the nature of innovative e-mail systems adoption and diffusion. The first phase was devoted to developing a dynamic TAM hypothesis of e-mail diffusion by using variables from literature. This part was principally theory driven while the second phase was used to validate the dynamics TAM model.

Corresponding Author: J. Macharia, United States International University, Nairobi, Kenya 


\section{Literature review}

The e-mail research problem and setting: E-mail may be defined as a computer-based system that facilitates written information exchange and storage (Sarosa and Zowghi, 2003). Modern e-mail application allows users to send and receive graphical and multimedia information as an attachment to the message body. Further, E-mail also is recognized for its capability to facilitate asynchronous communication (Sarosa and Zowghi, 2003). In higher education, e-mail has been used rather extensively for communication, learning and teaching. The main reason for wide spread use of e-mail is usually for learning activities like submitting assignments, the reduction of cost in official communication, printing and administration. E-mail is therefore replacing facsimile communication and memo, handoutsandsignment printing. The use of the later by students and teachers especially for course assignments is quite expensive without using e-mail. Moreover, the greatest weakness of paper submission of assignments is the lack of access to university instructor's submission office 24/7/365 and the inability to facilitate students in meeting the deadline well above office hours. This phenomena is due to the fact that electronic communication tends to counter the development of co-presence situations between the student and the teacher (Isaac et al., 2008).

The e-mail application, frequently presents users with a contradictory circumstances. Albeit it is a valuable application, the emerging trend of spending too much valuable time using e-mail due to the result of spam or naturally increasing e-mail traffic could create taxing and frustrating situations and low users productivity (Kanungo and Jain, 2008). Today, many people have more than one e-mail address and complain about the volumes of e-mails they get from genuine sources as well as spam mail and e-mails from marketing agents. The reason for complaining is the time they spend opening especially in developing economies where the internet connections are slow, reading, archiving, deleting and replying. Interestingly, irrespective of how many messages an individual user gets, e-mail complaints are about equally strong whether they receive ten e-mails per day or hundreds of messages (Kanungo and Jain, 2008). According to Kanungo and Jain (2008), the justification of this phenomenon is that individual's outlook of what to do with e-mail messages is dynamic. When individuals get a handful messages, they treat them as individual correspondence and consider each message and its reply cautiously than when they receive a lot of messages, where most are deleted. Of great importance is the question of how e-mail influences learning. To get insight on this unanswered question, this paper investigates the behavioural intention of students to adopt and diffuse e-mail use in their learning activities. The setting for this research was higher education environmentand the main respondents were students with some form of ICT usage in their university degree program.

Technology Acceptance Model (TAM): The conservative Tchnology Aceptance Model (TAM) constructs comprise perceived usefulness, perceived ease of useand intention to use Information System (IS) (Davis et al., 1989). Several preceding researchers have established the role of these constructs in predicting users intention to use an innovative technology such as e-mail (Chau and $\mathrm{Hu}, 2001$; Davis et al., 1989). Irrefutably, the introduction of a novel e-mail system represents a new technology and accordingly, it is coherent to include the TAM constructs to understand the adoption and diffusion of the new e-mail system (Kanungo and Jain, 2008). Other TAM research have postulated that people are expected to have a positive and encouraging behavioural intention toward using a new technology if they think that the technology is useful (Venkatesh and Bala, 2008; Davis et al., 1989). Further, several studies have revealed that perceived usefulness has a positive influence on behavioural intention (Davis, 1989; Venkatesh and Bala, 2008). The requirement to use e-mail in universities and the need to cope with changes in the e-mail system may increase the already significant levels of study stress of students and thus makes this study on student's behavioural intention timely and relevant. The study has deployed the known TAM constructs in addition to contextual variables.

\section{Theory and hypothesis formulation}

Technology adoption and usage: Much interest has been created over the years to the successful adoption, diffusion and use of Information and Communication Technologies (ICT) by institutions such as universities (Fink and Disterer, 2006). Technology adoption is the set of practices and factors related to an institution or individual selecting, deploying and sustaining the use of a technology. Consistent with the technology acceptance literature, adoption of a technology-based product could also be referred to as acquiring a technology-based appliance such as a mobile phone or subscribing to a technology-based service like the broadband wireless service. In addition, following previous technology usage studies (Davis et al., 1989) an individual usage of a technology-based product as is defined a person's actual 
usage of the technology for personal or research related purposes. According to Rogers (1995), the technology diffusion literature typically operationalizes adoption behaviour as an individual's adoption time-that is, the elapsed time between market introduction of an innovative product and the individual's first-time acquisition of it. The literature review of previous studies involving technology acceptance and usage reveals that technology usage is a intricate phenomenon; they propose focusing on measures that can be expected to relate closely to the other constructs within the Normological network (Burton-Jones and Hubona, 2005). Following this line of thought, we focus on a variety of use in student learning.

Although, previous studies provide dependable proof of those beliefs that are specific to a target technology that affect technology acceptance, majority of these studies do not compare the determinants of adoption with those of usage.

An exception is the study by Karahanna et al. (1999), who posits that perceived ease of use of Microsoft's Windows affects potential adopters intention to adopt the technology but has no effect on actual users sustained usage intention.

In addition to the target-specific beliefs, researchers found evidence of some personal, environmental, technologicaland organizational factors affecting technology acceptance. The personal variables include: Individual Factors: Gender, Age, Education Level, Experience, Voluntariness, Access to ICTsand Exposure to ICTs (Lam et al., 2008).

Compared to the studies on the foregoing factors that influence technology acceptance, relatively few researchers have examined the contextual variables such as Access to ICTs and Exposure to ICTs on the E-mail technology artefact. On the other hand, the technological factors variables that have been examined include Job relevance, perceived enjoyment, computer anxiety, computer self-efficacy (Venkatesh and Bala, 2008). Nevertheless, aside from using other technologies other than e-mail, most of these studies have been done in the US and Canada and hence their validity in developing economies has been questioned. On the whole, despite their limitations, the foregoing studies provide evidence suggesting that the individual and technological factors may individually affect technology acceptance by individuals and or organizations. Table 1 shown the variables of the dynamic model and we explain these effects and develop hypotheses about them that have been investigated in this study.

\section{Hypotheses}

Behaviour intention: The TAM asserts that intention is a proper proxy to examine and predict a user's behaviour toward a particular technology or system. Results from much research have shown consistent results showing a significant correlation between Behaviour Intention (BIU) and usage behaviour.

Moreover, the path from behavioural intention to behaviour is significant in the TAM, TPB and DTPB models. User Behaviour is largely influenced by Behavioural Intention (BIU), so BIU plays an important role in predicting usage behaviour. But it is important to note that BIU is more predictive of usage behaviour when individuals have had prior experience with the technology. Accordingly, the following hypothesis is introduced:

$\mathbf{H}_{1}$ : There is a positive influence of behavioural intention on the actual usage of e-mail.

Perceived usefulness: Ramdani and Kawalek (2008) argues that there are very few researches that have investigated the influence of technological factors in the context of small business.

Table 1: Technological factors definitions

\begin{tabular}{|c|c|c|}
\hline Determinants & Source & Definition \\
\hline Perceived usefulness & Davis et al., 1989 & $\begin{array}{l}\text { The degree to which a person believes that e-mail system would enhance his or her } \\
\text { studies performance }\end{array}$ \\
\hline Perceived ease of use & Davis et al., 1989 & The degree to which a person believes that e-mail system would be free of effort \\
\hline Study relevance & Venkatesh and Davis, 2000 & $\begin{array}{l}\text { The degree to which a student believes that the e-mail system is applicable to his or } \\
\text { her studies }\end{array}$ \\
\hline Behavioural intention & $\begin{array}{l}\text { Davis et al., 1989, Ajzen } \\
\text { and Fishbein, 1980: } 288\end{array}$ & The extent to which an individual intends to perform a specific behaviour \\
\hline Computer self-efficacy & $\begin{array}{l}\text { Compeau and Higgins, } \\
1995 \mathrm{a}, 1995 \mathrm{~b}\end{array}$ & $\begin{array}{l}\text { The degree to which an individual believes that he or she has the ability to perform } \\
\text { a septic task/assignment using the computer }\end{array}$ \\
\hline Computer anxiety & Venkatesh, 2000 & $\begin{array}{l}\text { The degree of an individual's apprehension, or even fear, when she/he is faced with the } \\
\text { possibility of using computers }\end{array}$ \\
\hline Perceived enjoyment & Venkatesh, 2000 & $\begin{array}{l}\text { The extent to which the activity of using e-mail system is perceived to be enjoyable } \\
\text { in its own right, aside from any performance consequences resulting from system use }\end{array}$ \\
\hline
\end{tabular}


Consequently, there are even few studies in higher education that have investigated the usefulness of E-mail in student learning. Nonetheless, technology adoption and diffusion research (Rogers, 1995; Mathieson, 1991; Kwon and Zmud, 1987) have found that perceived usefulness factor influences technology adoption and usage significantly and positively (Venkatesh and Bala, 2008; Ndubisi, 2007; Morris and Venkatesh, 2000; Musa, 2006; Kwon and Zmud, 1987).

Further, PU has also been reported to have significant and positive influence on the behavioural intention of technology users (Venkatesh and Bala, 2008). Accordingly, the following hypothesis is introduced:

$\mathbf{H}_{2}$ : There is a positive influence of perceived usefulness on the intention to adopt E-mail.

Perceived ease of use: Although, many researchers have studied the relations between perceived ease of use and perceived usefulness, the finding of this relation remains conflicting.

For example, Gefen and Straub revealed that the relation was not significant in explaining e-mail acceptance as a technology on the other hand others like (Venkatesh and Bala, 2008) proved otherwise. The case of Internet shopping, assumes that both variables are strongly linked based on the argument that an Internet user who perceives that purchasing through Internet is effortless should in turn develop a tendency to perceive it as useful.

This is supported by the fact that an internet user would fundamentally try to shape his/her perception of Internet shopping based on his/her experiences in engaging in internet shopping and the ease in which the activity was executed. Therefore, it hypothesize that:

$\mathbf{H}_{3}$ : There is a positive influence of perceived ease of use on the intention to adopt e-mail.

$\mathbf{H}_{4}$ : There is a positive influence of perceived ease of use on perceived usefulness of e-mails.

Subjective norm: Subjective norm has been found in TAM2 to positively influence perceived usefulness through processes of internalization.

In addition it theorizes that the effect of subjective norm on both, perceived usefulness and behavioral intention will attenuate over time as users increase their experience with the ICT artifact (Venkatesh and Bala, 2008). At an educational institution, the cases of freshers, new faculty and staff will always arise every semester.
The pressure put on them by their peers may have an effect on their adoption and diffusion of the ICTs such as e-mail that they encounter either in the institution, or out in the general environment to accomplish their task. Conequently this variable is given considertaion in the model of this research. We therefore hypothesise:

$\mathbf{H}_{5}$ : Subjective Norm will positively influence the perceived usefulness.

Studies relevance: According to Venkatesh and Bala (2008), TAM 3 which is an updated version of technology acceptance model includes social influence processes that is measured by variables like Subjective Norm, Voluntariness and cognitive instrumental processes that is measured by variables such as studies relevance (Chen and Corkindale, 2008).

These variables that have not been previously tested on e-mail have been included in the research model. We therefore hypothesize that:

$\mathbf{H}_{\mathbf{6}}$ : There is a positive influence of studies relevance of the e-mails to perceived ease of use.

Voluntaries: Venkatesh and Davis (2000) defines the level of voluntariness as the extent to which potential adopters of a technology perceive the adoption decision to be nonmandatory. Institutions often require their students, faculty and even employees to use certain ICT artefacts. Nonetheless, research has established that some people will not agree to follow such institutional regulations.

The study by Venkatesh and Davis (2000) found that voluntariness has a moderating effect on the subjective norm on intention to use a system. Consequently, behavioural intentions vary between mandatory and voluntary usage (Sun and Zhang, 2006).

Venkatesh and Davis (2000) found that in the context of technology acceptance in voluntary usage settings, the influence of other users will weaken to non-significance over time with increasing experience with the target system due to increased experience (Venkatesh and Davis, 2000; Sun and Zhang, 2006). Further, Sun and Zhang (2006) found that voluntariness is considered a moderating variable in shaping behavioural intention to use a system. Therefore it hypothesize that:

$\mathbf{H}_{7}$ : Voluntariness of using the e-mails will influence perceived ease of use.

Computer self-efficacy: Venkatesh and Davis (2000) found that six factors significantly contribute to how 
users perceive the ease of use of specific ICT systems over time in an actual organization setting. One of this variables is computer self-efficacy, Self-efficacy has a strong direct influence on perceived ease of use but only an indirect influence on perceived usefulness through perceived ease of use (Lee et al., 2003a). Consequently this study hypothesis:

$\mathbf{H}_{\mathbf{8}}$ : Computer self-efficacy has a direct effect on perceived ease of use.

Perceived enjoyment: Perceived Enjoyment is defined as The extent to which the activity of using a specific system is perceived to be enjoyable in its own right, aside from any performance consequences resulting from system usage (Lee et al., 2003b).

Davis et al. (1989) found that perceived enjoyment was significantly related to PEoU. Further, found that perceived enjoyment is one of the six factors that significantly influence on how users perceive the ease of use of specific ICT systems over time in an actual organization setting. For e-mail, it hypothesis:

$\mathbf{H}_{\mathbf{9}}$ : Perceived enjoyment has a direct effect on perceived ease of use of e-mail.

Perceived Resources (PR): Several studies have posited that access to ICTs alone is not enough and hence in evaluating ICTs s adoption and diffusion we need to take into account both the range of ICTs the users are exposed to and the skills of people to actually make use of these ICTs to achieve the relevant functioning.

The functioning will among other factors be a product of users education, training, skills and exposure to ICTs. Although in the Maclay, Hawkins and Kirkman's study was for secondary school students, teachers and staff, they established that despite the limited exposure to ICTs, students, teachers and administrators attitudes and perceptions of ICTs artefacts such as computers and the internet were overwhelmingly positive.

While this disconnect may cause some concern that ICTs such as e-mail are over-hyped, it also suggests the tremendous enthusiasm over the new tools and their power to instil a willingness to accept related changes in education in general and in particular higher education.

It is therefore evidence from the preceding discussion, that there is a need to investigate the influence of exposure to ICTs (Musa, 2006; Musa et al., 2005 ) variable in adoption and diffusion of information systems. Therefore hypothesis the following:
$\mathbf{H}_{10}$ : Perceived Resources (PR) is positively related to perceived ease of use of e-mails.

Computer anxiety: Woszczynski et al. (2000) posits that even with the introduction of computers in elementary school and often earlier, many college students still exhibit computer anxiety that is fear, anxiety and frustration in computer interactions. He further argues that although students may exhibit a temporary decrease in computer anxiety during their university life as they get more exposed to ICTs and as computer experience increases, the anxiety may tend to subsequently reappear, even after undergoing several years of their training program or gaining more computer exposure and experience.

Nonetheless, in integrating computers in higher education, researchers have proposed that lower computer anxiety levels could be important factor in helping people learn computer skills and use computers and other ICT artefacts (Sam et al., 2005). ICTs that are frightening and difficult to use are less likely to be enjoyable for users. Also PEOU may also negatively relate to computer anxiety. Taking into account that PEOU is closely related to computer self-efficacy and that computer self-efficacy is confirmed to have significant influence on computer anxiety, it is expected that PEOU is significantly related to computer anxiety.

It is evident that computer anxiety may continue to be exhibited even after extensive training and years of exposure and experience with ICTs and hence training and widespread diffusion of ICTs such as e-mail into all facets of life may not overcome the underlying anxiety experienced by individuals utilizing computers (Woszczynski et al., 2000). Consequently, research is evidently needed to advance the analysis and the nature of the computer anxiety construct.

$\mathbf{H}_{11}$ : Computer anxiety has a direct effect on perceived ease of use.

Access to ICTS: Several studies (Musa, 2006; Musa et al., 2005) have indicated that access to ICTs is a precondition to its use by individuals. In most countries of Sub-Saharan Africa, the high cost of access to telecommunication services is an impediment to access to ICTs by individuals and institutions (Mutula, 2004). Mutula (2004) argues that this is exacerbated by the fact that ICTs have not successfully been incorporated in the development agenda of most countries as reflected in the lack of ICT policies and allocation of resources. In higher education, this has sphere consequences as indicated by 


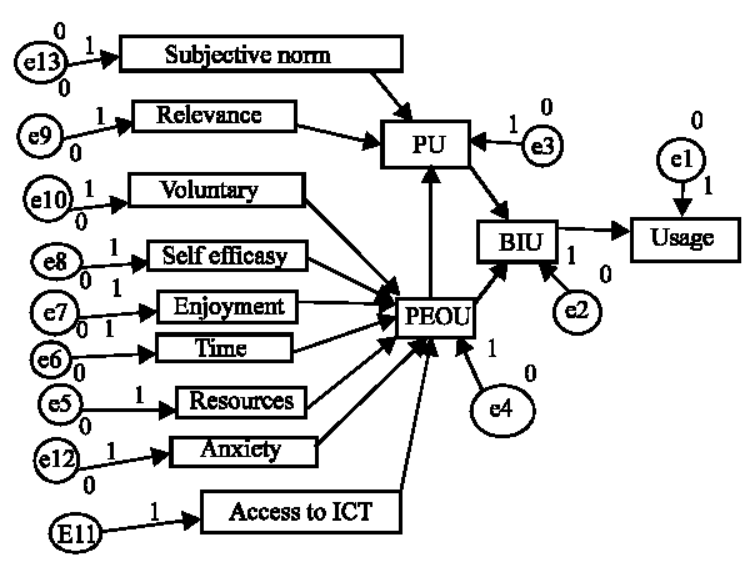

Fig. 1: Research model

the most recent web rankings of universities, where majority of African universities were in the tail. To help universities improve their rankings and hence their quality of programs, they need to understand technology acceptance Fig. 1. Consequently this study has found it pertinent to include access to ICTs as a variable for investigation, leading us to the hypothesis:

$\mathbf{H}_{12}$ : Access to ICTs is positively related to perceived usefulness and perceived ease of use of e-mail.

\section{MATERIALS AND METHODS}

Data collection: The target population consisted of students that have some form of computer and internet access in 7 public and 20 private universities in Kenya from which the actual sample of respondents of universities and students was selected. The respondents were asked to fill out the research questionnaire voluntarily.

Each student subject in our study was approached by a fellow student or faculty or ICT staff in their university who invited them to participate based on their response.

For this procedure to be similar to those for a postal survey, consideration was given to remove the researcher's possible influence on the subjects by using class lecturers and fellow students and ICT staff to collect the filled questionnaires.

Instrument: All the items used in this study to measure the constructs were adapted from prior studies (Table 1) with modifications to fit the specific context of this ILTs. Both the perceived usefulness and the ease of use were measured using four items from Davis et al. (1989) with two items used to measure behavioural intention (Ajzen and Fishbein, 1980) for the ILTs artefacts selected for this study namely-learning management systems.

A seven-point Likert scale with anchors ranging from very strongly disagrees to very strongly agree was used to ensure statistical variability among survey responses for all items in the questionnaire instrument except for the background and demographics data.

The measurement for usage was adapted from Teo et al. (1999) which is based on frequency of ILTs usage and duration of use. The SPSS 15.0 and AMOS 7.0 with multiple indicator structural equation analyses was used to analyze both the measurement model and the structural model.

\section{RESULTS}

\section{The measurement model}

Demographics: The assessment of the measurement model implies the calculation of three aspects of instrument validity namely item reliability, convergent validity and the discriminant validity. According to Grandon and Pearson (2004), it is necessary to start assessment of the measurement model before estimating path coefficients which indicates the sign and the power of the relationships since the item's weights and loadings indicate the strength of the measures (Ajzen and Fishbein, 1980).

Table 2 before the testing of assessment of the measurement model is shown, first some descriptive and demographic analysis to understand the data collected to test for response bias and for some common statistical assumptions.

Table 3 and 4 shows the categorization of demographic questions whereby it is evidence that $52.1 \%$ of the respondents were male. Most responses were from persons below the ages of 25; most participants also had above average ICTs experience and almost $90 \%$ were undergraduates in 1-4 year of their study.

Measurement models: In this study, the measurement model for all constructs ( $\mathrm{N}=1092$ ) was assessed. The constructs show evidence of strong psychometric properties and satisfied the required criteria of reliability, convergent and discriminant validity.

Table 5 shows that the item loadings were greater than or at least equal to 0.70 . Further, all across loadings except four of them were all $>0.30$. Therefore, convergent 
Table 2: Item operationalization of key model factors constructs

\begin{tabular}{|c|c|c|c|}
\hline Construct & Items & Code & Items \\
\hline \multirow[t]{4}{*}{ Perceived Usefulness (PU)* } & \multirow[t]{4}{*}{4} & PU1 & Using e-mail improves my performance \\
\hline & & PU2 & in my learning and study \\
\hline & & PU3 & Using e-mail in my learning/study increases my learning and study \\
\hline & & PU4 & $\begin{array}{l}\text { Using e-mail enhances my effectiveness in my learning and study. I find e-mail to be useful in my } \\
\text { learning and study }\end{array}$ \\
\hline \multirow[t]{4}{*}{ Perceived Ease of Use (PEOU)* } & \multirow[t]{4}{*}{4} & PEOU1 & Learning to use e-mail is easy for me \\
\hline & & PEOU2 & Interacting with e-mail does not require a lot of my mental effort \\
\hline & & PEOU3 & I find e-mail to be easy to use \\
\hline & & PEOU4 & I find it easy to get e-mail to do the work I want it to do \\
\hline \multirow[t]{3}{*}{ Relevance to Studies (REL)* } & \multirow[t]{3}{*}{3} & REL1 & In my studies, usage of the e-mail is important \\
\hline & & REL2 2 & In my studies, usage of the e-mail is relevant \\
\hline & & REL3 & The use of e-mail is pertinent to my various studies-related tasks \\
\hline \multirow[t]{2}{*}{ Behavioural Intension (BIU) } & \multirow[t]{2}{*}{1} & BIU1 & I intend to use e-mail for my learning and studies \\
\hline & & BIU2 & I intend to use the e-mail for academic and personal communications \\
\hline \multirow[t]{3}{*}{ Perceived Enjoyment (ENJ) } & \multirow[t]{3}{*}{3} & ENJ1 & I find using ICTs to be enjoyable \\
\hline & & ENJ2 & The actual process of using ICTs is pleasant \\
\hline & & ENJ3 & I have fun using ICTs \\
\hline \multirow[t]{4}{*}{ Computer Anxiety (CANX) } & \multirow[t]{4}{*}{4} & CANX1 & Computers do not scare me at all \\
\hline & & CANX2 & Working with a computer makes me nervous \\
\hline & & CANX3 & Computers make me feel uncomfortable \\
\hline & & CANX4 & Computers make me feel uneasy \\
\hline \multirow[t]{4}{*}{ Computer Self-Efficacy (CSE) } & \multirow[t]{4}{*}{3} & CSE1 & I could complete the studies using a software package ... \\
\hline & & CSE2 & ... if there was no one around to tell me what to do as I go \\
\hline & & CSE3 & ...if I had just the built-in help facility for assistance \\
\hline & & CSE4 & $\begin{array}{l}\text {...if someone showed me how to do it first. ... if I had used similar packages before this one to do } \\
\text { the same studies }\end{array}$ \\
\hline \multirow[t]{3}{*}{ Voluntariness (VOL)* } & \multirow[t]{3}{*}{3} & VOL1 & My use of ICTs is voluntary \\
\hline & & VOL2 & My supervisor does not require me to use ICTs \\
\hline & & VOL3 & Although it might be helpful, using ICTs is certainly not compulsory in my studies \\
\hline \multirow[t]{4}{*}{ Access to ICTs (AC) } & \multirow[t]{4}{*}{6} & $\mathrm{AC} 1$ & I access university computers for my studies \\
\hline & & $\mathrm{AC} 2$ & I access personal computer at home for my use \\
\hline & & $\mathrm{AC} 3$ & I access personal computer at cyber cafe for my use \\
\hline & & $\mathrm{AC} 4$ & I access the Intemet/www inside the university. I access my e-mail inside the university \\
\hline \multirow[t]{3}{*}{ Perceived Resources (PR) } & \multirow[t]{3}{*}{3} & PR1 & There is enough hardware and software for accessing and using Internet and the World Wide Web \\
\hline & & PR2 & $\begin{array}{l}\text { There is enough documentation and tutorials to guide me in accessing and using Internet and the } \\
\text { World Wide Web }\end{array}$ \\
\hline & & PR3 & I have enough time for accessing and using Internet and the World Wide Web \\
\hline
\end{tabular}

and discriminant validity was supported by the results of this study. In Table 5, internal consistency reliabilities Cronbach's alpha were all $>0.5$ for all constructs measured.

In this study, AVE is calculated as follows: (sum of squared factor loadings)/[(sum of squared factor loadings $)+($ sum of error variances)]. Table 6 shows the square root of the Average Variance Extracted (AVE) for each construct was higher than the Pearson correlations across constructs.

These evidence of strong psychometric properties were consistent with several previous studies employing these constructs and measures (Venkatesh and Bala, 2008; Davis, 1989; Davis et al., 1989. The results shown in Table 6 are consistent with previous research including Venkatesh and Bala (2008).

Explaining intention and usage: The results of Table 7 shows the effects of perceived usefulness, perceived ease of use and subjective norm on behavioural intentions
Table 3: Demography results

\begin{tabular}{lrr}
\hline Respondents & Number & Percent \\
\hline Gender & 569 & \\
Male & 523 & 52.10 \\
Female & 1092 & 47.90 \\
Total & & 100.00 \\
E-mail experience & 545 & \\
$0<\leq 1$ & 285 & 49.90 \\
$1<\leq 2$ & 144 & 26.10 \\
$2<\leq 3$ & 118 & 13.20 \\
$>3$ & 1092 & 10.80 \\
Total & & 100.00 \\
Year of study & 196 & \\
Year 1 & 209 & 17.90 \\
Year 2 & 276 & 19.10 \\
Year 3 & 300 & 25.30 \\
Year 4 & 36 & 27.50 \\
Doctorate & 1092 & 3.30 \\
Total & & 100.00 \\
\hline
\end{tabular}

by students to use E-mail for learning were significant. Consistent with much prior research, perceived usefulness was a strong determinant of intention to use and perceived ease of use was a significant secondary determinant. 
Asian J. Inform. Technol., 9 (3): 123-132, 2010

Table 4: Demographic results

\begin{tabular}{|c|c|c|c|c|c|c|c|}
\hline $\begin{array}{l}\text { Respondents } \\
\text { overall ICT experience }\end{array}$ & & mber & Percent & Respondent & & Number & Percent \\
\hline Poor & & 71 & 6.5 & $<15$ & & 175 & 16.0 \\
\hline Weak & 13 & 32 & 12.1 & $15-20$ & & 611 & 56.0 \\
\hline Below average & 15 & 52 & 13.9 & $21-25$ & & 148 & 13.6 \\
\hline Average & 36 & 60 & 33.0 & $26-30$ & & 72 & 6.6 \\
\hline Above average & 13 & 38 & 12.6 & $31-35$ & & 41 & 3.8 \\
\hline Good & 18 & 30 & 16.5 & $36-40$ & & 27 & 2.5 \\
\hline Excellent & & 54 & 4.9 & 4145 & & 11 & 1.0 \\
\hline Missing & & 5 & 0.5 & $>45$ & & 7 & 0.5 \\
\hline Total & $10 S$ & & 100.0 & Total & & 1092 & 100.0 \\
\hline Table 5: Measuremen & 1 reliability & & & & & & \\
\hline Factors & Code & Factor loadings & Cronbachs alpha & Factor & Code & Factor loadings & Cronbachs alpha \\
\hline Perceived Resources & PRHS01 & 0.820 & & Time Resource & TTIME & 0.780 & \\
\hline (PR) & PRHS02 & 0.849 & & (TR) & TIME 08 & 0.820 & 0.880 \\
\hline & PRHS03 & 0.834 & 0.903 & & TIME09 & 0.801 & \\
\hline & DOC04 & 0.765 & & Perceived Enjoyment & PE01 & 0.787 & \\
\hline & DOC05 & 0.740 & & $(\mathrm{PE})$ & $\mathrm{PE} 02$ & 0.874 & 0.849 \\
\hline & DOC06 & 0.655 & & & PE03 & 0.822 & \\
\hline Perceived Usefulness & PUEMA05 & 0.870 & & Computer Self & CSE01 & 0.566 & \\
\hline (PU) & PUEMA06 & 0.883 & & Efficacy (CSE) & CSE02 & 0.795 & 0.729 \\
\hline & PUEMA07 & 0.889 & 0.926 & & CSE03 & 0.777 & \\
\hline & PUEMA07_A & 0.832 & & & CSE04 & 0.722 & \\
\hline Perceived Ease of Use & PEOUEMA05 & 0.798 & & Actual Usage & EXPICT05 & 0.501 & 0.697 \\
\hline (PEOU) & PEOUEMA06 & 0.840 & 0.882 & $(\mathrm{AU})$ & EXPICT06 & 0.419 & \\
\hline & PEOUEMA07 & 0.843 & & Voluntariness & VEMA04 & 0.652 & \\
\hline & PEOULMS 07 & 0.728 & & & VEMA05 & 0.749 & 0.644 \\
\hline Relevance (REL) & REMA04 & 0.868 & & & VEMA06 & 0.837 & \\
\hline & REMA05 & 0.894 & 0.901 & Access to ICTs & AET04 & 0.854 & \\
\hline & REMA06 & 0.823 & & (AICT) & AET05 & 0.867 & 0.847 \\
\hline Computer & $\mathrm{CA} 02$ & 0.830 & & Behavioural Intention & BIU03 & 0.837 & \\
\hline & $\mathrm{CS} 03$ & 0.880 & 0.867 & (BIU) & BПU04 & 0.856 & 0.815 \\
\hline & $\mathrm{CS} 04$ & 0.842 & & & & & \\
\hline
\end{tabular}

Table 6: Discriminant validity-comparing SQRT(AVEs) and pearson correlations

\begin{tabular}{|c|c|c|c|c|c|c|c|c|c|c|c|c|}
\hline Factors & $\mathrm{PR}$ & $\mathrm{PU}$ & PEOU & PEL & $\mathrm{CA}$ & TR & $\mathrm{PE}$ & CSE & $\mathrm{AU}$ & VOL & AICT & $\mathrm{BIU}$ \\
\hline AVE & 0.91 & 0.93 & 0.93 & 0.93 & 0.91 & 0.92 & 0.93 & 0.90 & 0.77 & 0.90 & 0.92 & 0.94 \\
\hline \multirow{2}{*}{$\begin{array}{l}\text { SQRT (AVE) } \\
\text { Perceived Resources (PR) }\end{array}$} & 0.96 & 0.96 & 0.96 & 0.97 & 0.96 & 0.96 & 0.97 & 0.95 & 0.88 & 0.95 & 0.96 & 0.97 \\
\hline & 1 & & & & & & & & & & & \\
\hline Perceived Usefulness (PU) & $-107^{* *}$ & 1 & & & & & & & & & & \\
\hline Perceived Ease Of Use (PEOU) & $-151^{* *}$ & $-344^{* *}$ & 1 & & & & & & & & & \\
\hline Relevance (REL) & $-135^{* *}$ & $-321^{* *}$ & $-245^{* *}$ & 1 & & & & & & & & \\
\hline Computer Axiety (CA) & $-226^{* *}$ & $-0.219^{* *}$ & $-0.194^{* *}$ & $-0.143^{* *}$ & 1 & & & & & & & \\
\hline Time Resource (TR) & $-549^{* *}$ & $0.156^{* *}$ & $-207^{* *}$ & $-164^{* *}$ & $-133^{* *}$ & 1 & & & & & & \\
\hline Perceived Enjoyment (PE) & 0.047 & $-364^{* *}$ & $-303^{* *}$ & $-279^{* *}$ & $-0.298^{* *}$ & $-083^{* *}$ & 1 & & & & & \\
\hline Computer Self Efficasy (CSE) & $0.164^{* *}$ & $0.272^{* *}$ & $0.322^{* *}$ & $0.210^{* *}$ & $-0.018^{* *}$ & $0.159^{* *}$ & $0.303^{* *}$ & 1 & & & & \\
\hline Actual usage (AU) & $-399^{* *}$ & $-254^{* *}$ & $-285^{* *}$ & $-294^{* *}$ & $-0.035^{* *}$ & $0.300^{* *}$ & $-214^{* *}$ & -167 & 1 & & & \\
\hline Voluntariness & 0.05 & 0.014 & $0.101^{* *}$ & $-0.086^{* *}$ & $-161^{* *}$ & $0.056^{* *}$ & $-105^{* *}$ & $0.093^{* *}$ & 0.024 & & & \\
\hline Access to ICTs (AICT) & $-274^{* *}$ & $0.180^{* *}$ & $-186^{* *}$ & $-162^{* *}$ & $-078^{* *}$ & $-256^{* *}$ & $-123^{* *}$ & $-117^{* *}$ & $-409^{* *}$ & $-097^{* *}$ & 1 & \\
\hline Behavioural Intention (BIU) & $-163^{* *}$ & $-338^{* *}$ & $-224^{* *}$ & $0.311^{* *}$ & $-0.180^{* *}$ & $-232^{* *}$ & $-303^{* *}$ & $-234^{* *}$ & $-311^{* *}$ & $0.029^{* *}$ & $-188^{* *}$ & 1 \\
\hline \multicolumn{13}{|c|}{ Correlation is significant at the 0.01 level (2-tailed) } \\
\hline \multicolumn{13}{|c|}{ Table 7: Regression weights: (Group number 1-Default model) } \\
\hline Factors & Estimate & \multicolumn{2}{|c|}{ SE } & \multicolumn{2}{|c|}{ C.R. } & \multicolumn{2}{|r|}{$\mathrm{p}$-value } & \multicolumn{3}{|c|}{ Hypothesis } & \multicolumn{2}{|l|}{ Status } \\
\hline $\mathrm{PEOU}<\mathrm{PE}$ & 0.175 & \multicolumn{2}{|c|}{0.027} & \multicolumn{2}{|c|}{6.417} & \multirow{2}{*}{\multicolumn{2}{|c|}{ **** }} & & H9 & & Suppor & \\
\hline PEOU $<$ CSE & 261 & & & & 795 & & & & H8 & & Suppor & \\
\hline $\mathrm{PEOU}<\mathrm{CA}$ & 34 & 0.0 & & & 039 & & 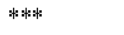 & & H11 & & Suppor & \\
\hline PEOU $<$ PRT & 14 & & 24 & & 668 & & ****** & & H13 & & Suppor & \\
\hline PEOU $<$ VOL & 661 & & 25 & & 475 & & 0.013 & & $\mathrm{H} 7$ & & Suppor & \\
\hline PEOU $<$ AICT & 771 & 0.0 & & & 696 & & ****** & & H12 & & Suppor & \\
\hline PEOU $<$ PR & 34 & & 25 & & 335 & & 0.182 & & H10 & & Not Su & ported \\
\hline $\mathrm{PU}<\mathrm{PEOU}$ & 247 & 0.0 & 27 & & 023 & & ****** & & H4 & & Suppor & \\
\hline PU $<$ REL & 201 & 0.0 & 25 & & 073 & & ****** & & H6 & & Suppor & \\
\hline $\mathrm{PU}<\mathrm{SN}$ & 67 & & 28 & & 014 & & *****: & & H5 & & Suppor & \\
\hline $\mathrm{BIU}<\mathrm{PU}$ & 211 & 0.0 & 29 & & 183 & & ***** & & $\mathrm{H} 2$ & & Suppor & \\
\hline BIU $<$ PEOUU & 52 & 0.0 & 28 & & 822 & & 0.068 & & H3 & & Not Su & ported \\
\hline $\mathrm{BIU}<\mathrm{SN}$ & 367 & 0.0 & 28 & & 044 & & 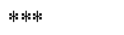 & & H14 & & Suppor & \\
\hline $\mathrm{BIU}<\mathrm{AICT}$ & 975 & 0.0 & 19 & & 928 & & ****** & & H15 & & Suppor & \\
\hline$\underline{\mathrm{AU}}<\mathrm{B} \Pi \mathrm{U}$ & 86 & 0.0 & 37 & & 541 & & $* * * * *$ & & $\mathrm{H} 1$ & & Suppor & \\
\hline
\end{tabular}

Note: **** $\mathrm{p}<0.001$ 
The correlations between intention and usage behaviour were found to be 0.31 . Thus consistent with previous studies, intention fully mediated the effects of subjective norm, perceived usefulnessand perceived ease of use on mail technology usage behaviour.

\section{DISCUSSION}

Majority of the hypothesis of this study were strongly supported by the measurement results shown in Table 6. Encompassing both social influence processes (subjective norm and voluntariness) and cognitive instrumental processes (e-mail relevance to studiesand perceived ease of use). The study has revealed that availability of ICTs influences both perceived ease of use and behavioural intentions to use e-mails. This is a dimension that has been ignored by many of the study in previous studies especially those done in the US and Canada where ICTs are available readily. The model of Table 7 provides a detailed account of the major factors influencing perceived usefulness, explaining up to $36 \%$ of the variance in this vital driver of behavioural intentions to use e-mail. Furthermore, the model extends TAM by showing that subjective norm exerts a dominant and significant direct effect on technology usage intentions over and above perceived usefulness and perceived ease of use of the system. The influence of social factors processes was consistent with Venkatesh and Davis (2000). The subjective norm factor significantly influenced perceived usefulness via both internalization, in which students incorporate social influences into their own usefulness perceptions and identification in which students use a system to gain status and influence within their peers and classmates and thereby improve their learning performance. In addition to these two indirect effects via perceived usefulness, subjective norm had a direct effect on behavioural intentions. On the other hand, previous research found that no significant role for social influences in voluntary contexts (Davis et al., 1989; Mathieson, 1991). This situation can be explained by the fact that as individuals gained direct experience with a system over time, they relied less on social information in forming perceived usefulness and intention but continued to judge a system's usefulness on the basis of potential status benefits resulting from use.

\section{CONCLUSION}

The e-mail technology is useful for learning at universities and that the subjective norm variable is the most dominant influence of intensions to use and consequently usage of the e-mail system. This revelation can now be exploited by universities by ensuring that if some courses are using e-mail for communication and course research, this will have positive effects on non users. Universities can therefore exploit these findings by deploying e-mail systems that add value to the learning environment.

\section{REFERENCES}

Ajzen, I. and M. Fishbein, 1980. Understanding Attitudes and Predicting Social Behavior. Prentice-Hall, Englewood Cliffs, NJ., ISBN-13: 978-0139364358.

Burton-Jones, A. and G.S. Hubona, 2005. Individual differences and usage behavior: Revisiting a technology acceptance model assumption. Data Base Adv. Inform. Syst., 36: 58-77.

Chau, P. and P. Hu, 2001. Information technology acceptance by individual professionals: A model comparison approach. Decision Sci., 32: 699-719.

Chen, Y.H.H. and D. Corkindale, 2008. Towards an understanding of the behavioral intention to use online news services. Internet Res., 18: 286-312.

Davis, F.D., R.P. Bagozzi and P.R. Warshaw, 1989. User acceptance of computer technology: A comparison of two theoretical models. Manage. Sci., 35: 982-1003.

Davis, F.D., 1989. Perceived usefulness, perceived ease of use and user acceptance of information technology. Manage. Inform. Syst. Q., 13: 319-340.

Fink, D. and G. Disterer, 2006. International case studies: To what extent is ICT infused into the operations of SMEs. J. Enterprise Inform., 19: 608-624.

Grandon, E. and J.M. Pearson, 2004. E-commerce adoption: Perceptions of managers/owners of small and medium sized firms in Chile. Commun. Assoc. Inform. Syst., 13: 81-102.

Isaac, H., M. Kalika and N.B. Charki, 2008. An empirical investigation of e-mail use versus face-to-face meetings: Integrating the napoleon effect perspective. Commun. Assoc. Inform. Syst., 22: 1-17.

Kanungo, S. and V. Jain, 2008. Modeling e-mail use: A case of e-mail system transition. Syst. Dyn. Rev., 3: 299-319.

Karahanna, E., D.W. Straub and N.L. Chervany, 1999. Information technology adoption across time: A cross-sectional comparison of pre-adoption and post-adoption beliefs. MIS Quart., 23: 183-213.

Kwon, T. and R. Zmud, 1987. Unifying the Fragmented Models of Information Systems Implementation. In: Critical Issues in Information Systems Research, Hirshheim, R. (Ed.). John Wiley and Sons, NY., ISBN:0-471-91281-6, pp: 227-251. 
Lam, S.Y., J. Chiang and A. Parasuraman, 2008. The effects of the dimensions of technology readiness on technology acceptance: An empirical analysis. J. Interact. Market., 22: 19-39.

Lee, J.S., H. Cho, G. Gay, B. Davidson and A. Ingraffea, 2003a. Technology acceptance and social networking in distance learning. Educ. Technol. Soc., 6: 50-61.

Lee, Y., A.K. Kozar and K. Larsen, 2003b. The technology acceptance model: Past, present and future. Commun. Assoc. Inform. Syst., 12: 752-780.

Mathieson, K., 1991. Predicting user intentions: Comparing the technology acceptance model with the theory of planned behavior. Inform. Syst. Res., 2: 173-191.

Morris, M. and V. Venkatesh, 2000. Age differences in technology adoption decisions: Implications for a changing work force durham. Personnel Psychol., 53: 375-403.

Musa, P.F., 2006. Making a case for modifying the technology acceptance model to account for limited accessibility in developing countries. Inform. Technol. Dev., 12: 213-224.

Musa, P.F., P. Meso and V.W. Mbarika, 2005. Toward sustainable adoption of technologies for human developmentin sub-saharan in Africa: Precursors, diagnostics and prescriptions. Commun. Assoc. Inform. Syst., 15: 1-31.

Mutula, S., 2004. IT diffusion in Sub-Saharan Africa: Implications for developing and managing digital libraries. New Library World, 105: 281-289.

Ndubisi, N.O., 2007. Evaluating the direct and indirect impact of traits and perceptions on technology adoption by women entrepreneurs in Malaysia. Acad. Entrepreneurship J., 13: 1-20.
Ramdani, B. and P. Kawalek, 2008. Predicting Smes Willingness to Adopt ERP, CRM, SCM and EProcurement Systems. University of Manchester, Manchester.

Rogers, E.M., 1995. Diffusion of Innovations. 4th Edn., Free Press, New York.

Sam, H.K., A.E. Othman and Z. Nordin, 2005. Computer self-efficacy, computer anxiety and attitudes toward the internet: A study among undergraduates in unimas. Educ. Technol. Soc., 8: 205-219.

Sarosa, S. and D. Zowghi, 2003. Strategy for adopting information technology for SMEs: Experience in adopting e-mail within an indonesian furniture company. Electronic J. Inform. Syst. Evaluat., 6: 165-176.

Sun, H. and P. Zhang, 2006. Applying markus and robeys causal structure to examine user technology acceptance research: A new approach. J. Inform. Technol. Theor. Appl., 8: 21-40.

Teo, S.H.T., V.K.G. Lim and R.Y.C. Lai, 1999. Intrinsic and extrinsic motivation in internet usage. Omega, 27: 25-37.

Venkatesh, V. and F.D. Davis, 2000. A theoretical extension of the technology acceptance model: Four longitudinal field studies. Manage. Sci., 46: 186-204.

Venkatesh, V. and H. Bala, 2008. Technology acceptance model 3 and a research agenda on interventions. Decision Sci., 39: 273-315.

Woszczynski, A., L. Lazar and J. Walker, 2000. Does training reduce computer anxiety. Proceedings of the 7th Annual Conference of the Southern Association for Information Systems, (ISAIS'00), Kennesaw State University, pp: 115-118. 